\title{
$\infty \sqrt{1}$ Stroke and \\ Cerebral microvascular dysfunction and neurodegeneration in dementia
}

Feng $\operatorname{Han}^{\odot}$

To cite: Han F. Cerebral microvascular dysfunction and neurodegeneration in dementia. Stroke and Vascular Neurology 2019;4: e000213. doi:10.1136/ svn-2018-000213

Received 19 November 2018 Revised 16 April 2019 Accepted 23 April 2019 Published Online First 24 June 2019

Check for updates

(C) Author(s) (or their employer(s)) 2019. Re-use permitted under CC BY-NC. No commercial re-use. See rights and permissions. Published by BMJ.

Key Laboratory of Cardiovascular and Cerebrovascular Medicine, School of Pharmacy, Nanjing Medical University, Nanjing, Jiangsu, China

Correspondence to Dr Feng Han;

fenghan169@njmu.edu.cn

\section{ABSTRACT} since 2003.
Maintaining normal learning and memory functions requires a high degree of coordination between neural and vascular cells. Basic and clinical studies have shown that brain microvasculature dysfunction activates inflammatory cells in the brain, leading to progressive neuronal loss and eventually dementia. This review focuses on recent studies aimed at identifying the molecular events that link cerebral microvascular dysfunction to neurodegeneration, including oxidative/nitrosative stress, cellular metabolic dysfunction, inflammatory signalling and abnormal synaptic plasticity. A better understanding of the coupling between vasculature and brain neurons and how this coupling is disrupted under pathological conditions is of great significance in identifying new diagnostic and treatment targets for dementia for which no new drugs have been approved

Accumulating evidence from epidemiological and postmortem studies suggests a close relationship among small vessel disease (SVD), aberrant neurovascular regulation and cognitive impairment. Dysregulation of cerebral blood flow and abnormal neural activity secondary to altered neurovascular coupling have been observed in the early stage of neurodegenerative diseases. However, the precise mechanism by which vascular dysfunction contributes to cognitive impairment remains poorly understood.

Aberrant peroxynitrite generation is a primary risk factor for vascular dysfunction. ${ }^{1-4}$ Patients with Alzheimer's disease (AD) exhibit clear cerebrovascular pathology and white matter injury due to microvascular infarction, suggesting an association of the cerebrovascular disease with neurodegenerative disorders. ${ }^{56}$ A possible contribution of nitrosative stress to $\mathrm{AD}$ pathology is indicated by the observation that peroxynitrite formation induced microvascular injury followed by $\beta$-amyloid accumulation in microvessels and parenchyma and eventual Glycogen synthase kinase-3 $\beta$ (GSK3 $\beta$ ) activation and hyperphosphorylation of tau proteins in the aged rat brain. $^{5}$ Supporting this suggestion, inhibition of nitrosative stress partially restored the decrease of phospho-CaMKII (Th286/287) and phospho-synapsin I (Ser603), increased the number of mature neurons in the hippocampus, and significantly improved cognitive function in mice with vascular dementia. ${ }^{7}$ Moreover, the inhibition markedly decreased peroxynitrite formation and downregulated NLRP3/caspase-1/IL-1 $\beta$ signalling in mice with bilateral carotid artery stenosis (figure 1). ${ }^{8}$

Damages to the neurovascular system are believed to be a major source of morbidity and mortality in chronic diseases such as diabetes. ${ }^{9}$ An alternation in hippocampal $\mathrm{Ca} 2+$ /calmodulin-dependent protein kinase $\mathrm{II}(\mathrm{CaMKII}) /$ Protein kinase C(PKC)/Protein kinase $\mathrm{A}(\mathrm{PKA})$ pathway may be partially responsible for the detrimental postdiabetic outcomes associated with cognitive dysfunction in diabetic models. ${ }^{10}$ Brain microvascular complications can lead to changes in brain structure and function. ${ }^{11} 12$ In vivo two-photon fluorescence microscopy reveals disturbances of cerebral capillary blood flow in diabetes which are exaggerated and associated with rapid cognitive decline after brain ischaemia. ${ }^{11}$ Accompanied by the disturbance of capillary blood flow and neurovascular damage, phospho-CaMKII (Thr286), phospho-synapsin I (Ser603) and phospho-GluR1 (Ser831) are dramatically decreased in the diabetic mice with ischaemia. ${ }^{11}$ Together, these findings suggest an active role for vascular factors in the pathogenesis of cognitive dysfunction. Further studies are needed to fully understand the changes in the microenvironment in the brain under the different pathological condition and the communication between components of the neurovascular unit.

Emerging studies have uncovered essential roles of endothelial molecules in brain function and behaviour. ${ }^{13-17}$ For example, brain endothelial cells have been suggested to be a natural gatekeeper for virus-induced sickness behaviour. ${ }^{18}$ The study further demonstrated an engagement of tissue-specific Interferon (IFN) receptor chain 1 and established the signal transduction axis as a target for the treatment of the behavioural changes. ${ }^{18}$ Clinical studies suggest that endothelial thrombomodulin is closely associated with cerebral SVD severity, but cerebral endothelial activation in 


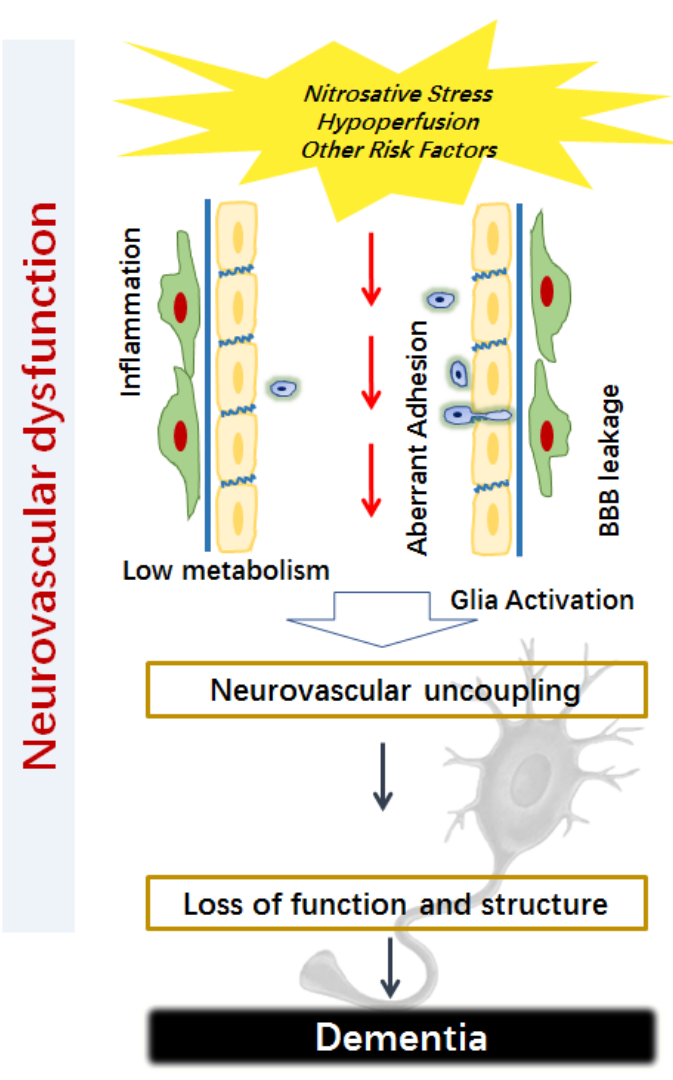

Figure 1 The schematic image is illustrating the possible relationship between cerebral microvascular dysfunction and neurodegeneration in dementia.

deep penetrating arteries did not. ${ }^{19}$ By using both endothelial-specific gene knockdown and neurobehavioural strategies, we found that deletion of the endothelial ErbB4 receptor-induced impairment in exploratory activity in adult mice and the effect was associated with reduced glucose transport and impaired energy metabolism of the brain. ${ }^{20}$ More recently, the study showed that brain endothelial-derived semaphorin $3 \mathrm{G}$ might act as a synaptic organiser, regulating synaptic plasticity and hippocampal-dependent memory. ${ }^{21}$

A long list of endeavours are warranted to further tackle the mechanisms underlying the interaction between vascular and neuronal cells and the role of the interaction in dementia, including (1) studies using novel technologies including imaging from nanoscale to whole brain, high-throughput transcriptomics/proteomics screens and bioinformatics, (2) a deeper understanding of the dynamic regulation of neurovascular coupling by circulating factors including those implicated in dementia, and (3) further exploration of the role of exosomes, cytokines and microRNAs in neurovascular compartments. A combination of these approaches may allow for multidimensional analyses of the complex underlying molecular and cellular network, help discover novel biomarkers, and develop more effective diagnostic and treatment strategies for dementia.
Contributors FH is the sole author.

Funding This work was supported by the State Key Program of National Natural Science of China (grant number 81730101), the National Key Research and Development Program of China (grant number 2016YFE0125400), and the National Natural Science Foundation of China (grant number 81573411).

Competing interests None declared.

Patient consent for publication Not required.

Provenance and peer review Commissioned; externally peer reviewed. Data sharing statement No additional data are available.

Open access This is an open access article distributed in accordance with the Creative Commons Attribution Non Commercial (CC BY-NC 4.0) license, which permits others to distribute, remix, adapt, build upon this work non-commercially, and license their derivative works on different terms, provided the original work is properly cited, appropriate credit is given, any changes made indicated, and the use is non-commercial. See: http://creativecommons.org/licenses/by-nc/4.0/.

\section{REFERENCES}

1. Han F, Tao RR, Zhang GS, et al. Melatonin ameliorates ischemic-like injury-evoked nitrosative stress: Involvement of HtrA2/PED pathways in endothelial cells. J Pineal Res 2011;50:281-91.

2. Tao RR, Ji YL, Lu YM, et al. Targeting nitrosative stress for neurovascular protection: new implications in brain diseases. Curr Drug Targets 2012;13:272-84.

3. Han F, Chen YX, Lu YM, Ym L, et al. Regulation of the ischemiainduced autophagy-lysosome processes by nitrosative stress in endothelial cells. J Pineal Res 2011;51:124-35.

4. Wang CK, Ahmed MM, Jiang Q, et al. Melatonin ameliorates hypoglycemic stress-induced brain endothelial tight junction injury by inhibiting protein nitration of TP53-induced glycolysis and apoptosis regulator. J Pineal Res 2017;63:e12440.

5. Han F, Ali Raie A, Shioda N, et al. Accumulation of beta-amyloid in the brain microvessels accompanies increased hyperphosphorylated tau proteins following microsphere embolism in aged rats. Neuroscience 2008;153:414-27.

6. Miklossy J. Cerebral hypoperfusion induces cortical watershed microinfarcts which may further aggravate cognitive decline in Alzheimer's disease. Neurol Res 2003;25:605-10.

7. Wang XJ, Gao YP, Lu NN, et al. Endogenous Polysialic Acid Based Micelles for Calmodulin Antagonist Delivery against Vascular Dementia. ACS Appl Mater Interfaces 2016;8:35045-58.

8. Wang R, Yin YX, Mahmood Q, et al. Calmodulin inhibitor ameliorates cognitive dysfunction via inhibiting nitrosative stress and NLRP3 signaling in mice with bilateral carotid artery stenosis. CNS Neurosci Ther 2017;23:818-26.

9. Bogush M, Heldt NA, Persidsky Y. Blood Brain Barrier Injury in Diabetes: Unrecognized Effects on Brain and Cognition. $J$ Neuroimmune Pharmacol 2017;12:593-601.

10. Liao MH, Xiang YC, Huang JY, et al. The disturbance of hippocampal CaMKII/PKA/PKC phosphorylation in early experimental diabetes mellitus. CNS Neurosci Ther 2013;19:329-36.

11. Huang JY, Li LT, Wang H, et al. In vivo two-photon fluorescence microscopy reveals disturbed cerebral capillary blood flow and increased susceptibility to ischemic insults in diabetic mice. CNS Neurosci Ther 2014;20:816-22.

12. Mogi M, Horiuchi M. Neurovascular coupling in cognitive impairment associated with diabetes mellitus. Circ J 2011;75:1042-8.

13. Toth $P$, Tarantini S, Csiszar A, et al. Functional vascular contributions to cognitive impairment and dementia: mechanisms and consequences of cerebral autoregulatory dysfunction, endothelial impairment, and neurovascular uncoupling in aging. Am J Physiol Heart Circ Physiol 2017;312:H1-H20.

14. Obasi CN, Cruickshanks KJ, Nondahl DM, et al. Association of Biomarkers for Inflammation, Endothelial Dysfunction and Oxidative Stress with Cognitive Impairment. The Epidemiology of Hearing Loss Study (EHLS). Oxid Antioxid Med Sci 2012;1:169-73.

15. Kinzenbaw DA, Chu Y, Peña Silva RA, et al. Interleukin-10 protects against aging-induced endothelial dysfunction. Physiol Rep 2013;1:e00149.

16. Cahill-Smith S, Li JM. Oxidative stress, redox signalling and endothelial dysfunction in ageing-related neurodegenerative diseases: a role of NADPH oxidase 2. Br J Clin Pharmacol 2014;78:441-53.

17. Fujiyoshi K, Yamaoka-Tojo M, Minami Y, et al. Endothelial Dysfunction Is Associated with Cognitive Impairment of Elderly Cardiovascular Disease Patients. Int Heart J 2018;59:1034-40. 
18. Blank T, Detje CN, Spieß A, et al. Brain Endothelial- and EpithelialSpecific Interferon Receptor Chain 1 Drives Virus-Induced Sickness Behavior and Cognitive Impairment. Immunity 2016;44:901-12.

19. Giwa MO, Williams J, Elderfield K, et al. Neuropathologic evidence of endothelial changes in cerebral small vessel disease. Neurology 2012;78:167-74.
20. Wu G, Liu XX, Lu NN, Nn L, et al. Endothelial ErbB4 deficit induces alterations in exploratory behavior and brain energy metabolism in mice. CNS Neurosci Ther 2017;23:510-7.

21. Tan C, Lu NN, Wang CK, et al. Endothelium-Derived Semaphorin 3G Regulates Hippocampal Synaptic Structure and Plasticity via Neuropilin-2/PlexinA4. Neuron 2019;101:920-37. 